\title{
Non-fasting OGTT versus Fasting OGTT for screening of Hyperglycaemia in Pregnancy (HIP)
}

\author{
Shabeen Naz Masood', Nusrat Lakho', \\ Saira Saeed ${ }^{3}$, Yasir Masood ${ }^{4}$
}

\begin{abstract}
Objectives: To compare the reliability of non-fasting oral glucose tolerance test (OGTT) versus fasting OGTT for screening of hyperglycaemia in pregnancy (HIP).

Methods: This cross sectional analytic study was conducted by the Department of Obstetrics \& Gynaecology, Isra University Karachi Campus from October 2016 to April 2017. A total of 225 pregnant women irrespective of gestational age were included in the study. They underwent non fasting 75 grams OGTT. Venous plasma glucose was done 02 hours after the glucose load. Same women were advised to come again within three to seven days for fasting OGTT. Venous plasma glucose (VPG) was estimated in fasting and 2 hours post glucose load.

Results: Using the non-fasting OGTT, out of 204 women, 32 were diagnosed with hyperglycemia. All these 204 women were again called for fasting OGTT three to seven days after the initial non-fasting OGTT. Only nine were diagnosed with hyperglycemia, out of these nine women, seven women who were screen positive on non-fasting OGTT were found to be screen positive on fasting OGTT as well. However, only two women were additionally diagnosed with hyperglycemia who were initially screen negative on non-fasting OGTT. The non-fasting OGTT has diagnosed HIP with sensitivity of $77.7 \%$, specificity of $87.1 \%$, positive predictive value of $21.8 \%$ and negative predictive value of $98.8 \%$.

Conclusion: The use of the non-fasting OGTT at first antenatal visit may be a practical approach to detect the HIP as screening and diagnostic tool in the resource constrained settings.
\end{abstract}

KEYWORDS: Hyperglycemia in Pregnancy (HIP), Fasting OGTT, Non Fasting OGTT, GDM, Diabetes in Pregnancy (DIP).

doi: https://doi.org/10.12669/pjms.37.4.3979

How to cite this:

Masood SN, Lakho N, Saeed S, Masood Y. Non-fasting OGTT versus Fasting OGTT for screening of Hyperglycaemia in Pregnancy (HIP). Pak J Med Sci. 2021;37(4):1008-1013. doi: https://doi.org/10.12669/pjms.37.4.3979

This is an Open Access article distributed under the terms of the Creative Commons Attribution License (http://creativecommons.org/licenses/by/3.0), which permits unrestricted use, distribution, and reproduction in any medium, provided the original work is properly cited.

1. Dr. Shabeen Naz Masood, MBBS, MCPS, FCPS, PhD, DCPS

2. Dr. Nusrat Lakho, MBBS, FCPS.

3. Dr. Saira Saeed, MBBS, FCPS.

4. Dr. Yasir Masood, MD, MPH.

Department of Public Health,

Brown School, Washington University in St. Louis,

Missouri, USA.

1-3: Department of Obstetrics \& Gynaecology,

Isra University,

Karachi, Pakistan.

Correspondence:

Dr. Shabeen Naz Masood, MBBS, MCPS, FCPS, PhD, DCPS Professor \& Head Department of Obstetrics \& Gynaecology, Isra University, Karachi-Campus,

Karachi - Pakistan.

Email: sh_naz@yahoo.com

* Received for Publication:

December 12, 2020

* Revision Received:

March 18, 2021

* Revision Accepted:

April 2, 2021

\section{INTRODUCTION}

The prevalence of diabetes is increasing with almost equal proportions in men and women. Currently it is reported as high as $26.3 \%$ in developing countries like Pakistan. ${ }^{1}$ Gestational Diabetes Mellitus (GDM) is the most common medical disorder of pregnancy. It is reported to affect $15 \%$ of pregnant women worldwide. ${ }^{2-4}$

Maternal adiposity, insulin desensitizing effects of placental hormones, 5,6 genetic and epigenetic factors predispose Asian women to develop diabetes in pregnancy. ${ }^{7}$ In the absence of specific symptoms of diabetes in pregnancy, there is a need for universal screening of blood glucose in pregnancy. 
The screening method should be sensitive, reliable and patient friendly. It should also be diagnostic, cost effective and affordable in resource constraint settings.

The fasting OGTT recommended by World Health Organization (WHO) and IADPSG is considered as standard and confirmatory test to diagnose HIP. ${ }^{8}$ However, it requires women to come in fasting state, ${ }^{9}$ or stay fasted while waiting to be seen in busy clinical and laboratory settings. Multiple blood test and misconceptions about prolonged fasting and long travel distance to health facilities leads to non-compliance and inconvenience.Non-fasting OGTT is a modified version of WHO criteria, is one-step procedure, does not require fasting and requires single blood sample for blood glucose screening.

The rationale of performing non fasting OGTT is that, normoglycaemic women usually have normal insulin response when given glucose load, whereas a pregnant woman with diabetes will not be able to maintain euglycemia post meals and after glucose load. This may be due to higher insulin resistance and impaired insulin secretion. ${ }^{10}$

Non-fasting OGTT is more acceptable to women as they do not have to drink glucose solution empty stomach, causes less nausea and vomiting in pregnancy and involves less operational cost. IADPSG criteria requires multiple blood samples, extra cost, men power and additional resources which is an added burden to developing countries working with marginal health economies. However, the universal BG screening recommended by IADSPG panel of experts is less likely to miss any women with GDM and is a recognized screening methodology where resources permit. ${ }^{11}$

Rationale of study: In the present study nonfasting OGTT was compared with fasting oral glucose tolerance test to evaluate the sensitivity and specificity of non-fasting OGTT versus fasting OGTT.

\section{METHODS}

This cross-sectional study was done to evaluate sensitivity and specificity of non-fasting blood glucose screening versus fasting OGTT as the gold standard. This study was done as a part of World Diabetes Foundation (WDF) GDM Project in Pakistan (WDF 14-896). It was conducted at outpatient Department of Obstetrics and Gynaecology, Isra University Karachi Campus from October 2016 to April 2017.
Ethical approval: This study was approved by the Institutional Ethics Review Committee of AlIbrahim Eye Hospital, Isra University, Karachi Campus, Pakistan, with protocol number A-00076/2 on $3^{\text {rd }}$ March 2017.

Sample size was calculated from software openepi. com by taking statistical conditions of $5 \%$ margin of error and $95 \%$ confidence interval. Hypothesized $\%$ frequency of outcome factor in the population prevalence $\mathrm{P}=26.3 \%$ was cited from the study Reference \#2 IDF Diabetes Atlas. $6^{\text {th }}$ ed. The required sample size was derived to be 225 . The formula used in sample size calculation was mentioned below:

Sample size:

$$
\mathrm{n}=\left[\operatorname{DEFF}^{*} \mathrm{~Np}(1-\mathrm{p})\right] /\left[\left(\mathrm{d}^{2} / \mathrm{Z}^{2}{ }_{1-\mathrm{\alpha} / 2}^{*}(\mathrm{~N}-1)+\mathrm{p}^{*}(1-\mathrm{p})\right]\right.
$$

Sample Size: According to study design, following formula was used to calculate the sample size.

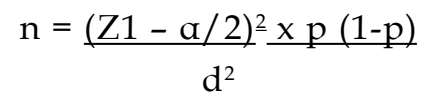

The required sample size was derived to be 225 women.

Inclusion Criteria: All pregnant women who consented for the study were included at first antenatal visit irrespective of gestational age and associated comorbidities for blood glucose screening.

Exclusion Criteria: Pregnant women with preexisting / diagnosed / confirmed cases of diabetes.

The data was collected on prespecified questionnaire by trained medical officer. Women were given 75 grams of glucose in $250 \mathrm{cc}$ of water irrespective of last meal to drink it slowly over a period of 3-5 minutes. Zero hour was considered when the women first sipped the glucose solution. Venous blood sample was collected after two hours of oral glucose load. The samples were centrifuged immediately and analyzed by the glucose peroxidase method using commercially available kit provided by Randox. All women who were subjected to non-fasting OGTT were requested to come back within 3-7 days with eight hours fasting. Venous blood sample was taken in fasting state and another blood sample was drawn two hours after $75 \mathrm{gm}$ glucose load. The cut off for fasting blood sugar and two hours post glucose load was taken as $\geq 126$ and $\geq 140 \mathrm{mg} / \mathrm{dl}$ respectively (WHO criteria).

Statistical Analysis: Statistical analysis was performed using Statistical Package for Social Sciences (SPSS) software for windows version 20.0. All continuous variables were presented as mean \pm standard deviation. Categorical variables were presented as frequency and percentages. 
Diagnostic accuracy of non-fasting OGTT and fasting OGTT was shown in 2x2 contingency table with sensitivity, specificity, positive predictive values and negative predictive values. To know the significance between different variables Chi-square test was applied. P-value $\leq 0.05$ was considered to be statistically significant.

\section{RESULTS}

Two hundred and twenty-Five, pregnant women were subjected to non-fasting OGTT, 21 women were dropped from the study because of vomiting and non-compliance. Using the non-fasting OGTT, out of 204 women, 32 were diagnosed with hyperglycemia. All these 204 women were again called for fasting OGTT 3-7 days after the initial non-fasting OGTT. Only nine were diagnosed with hyperglycemia, out of these nine women, seven women who were screen positive on non-fasting OGTT were found to be screen positive on fasting OGTT as well. However, only two women were additionally diagnosed with hyperglycemia who were initially screen negative on non-fasting OGTT. Fasting hyperglycaemia was detected in only one $(0.7 \%)$ woman with fasting OGTT.

Most of study participants were below 31 years of age with mean age of 25.5 with standard deviation of 9.3 . Among the screen positive women, $7(21.9 \%)$ were less than 25 year of age, $13(40.6 \%)$ were $26-30$ years and $12(37.5 \%)$ were more than 31 years of age. The mean age of screen positive women was 29 years and that of screen negative women was 26.9 years.

Women attended antenatal clinics at different periods of gestation, out of 32 screen positive women, 11 (5.3\%) attended outpatient department before 14 weeks of gestation, 18 (8.8\%) between 15 to 28 weeks and $3(1.4 \%)$ after 28 weeks of gestation. Mean gestational age at first antenatal visit was 21 weeks.

Table-I: Comparison of Diagnostic accuracy of non-fasting versus fasting OGTT $(\mathrm{n}=204)$

\begin{tabular}{lcccc}
\hline & \multicolumn{3}{c}{ Fasting OGTT } & \multirow{2}{*}{ Total } \\
\cline { 3 - 5 } & & GDM +ve & GDM -ve & \\
\hline \multirow{2}{*}{ Non-fasting } & Test +ve & 7 & 25 & 32 \\
OGTT & Test-ve & 2 & 170 & 172 \\
\hline \multirow{2}{*}{ Total } & 9 & 195 & 204 \\
\hline
\end{tabular}

Sensitivity $77.78 \%$, Specificity $87.18 \%$,

PPV $21.88 \%$, NPV 98.84\%.
The non-fasting OGTT method has diagnosed HIP with sensitivity of $77.7 \%$, specificity of $87.1 \%$, positive predictive of $21.8 \%$ and negative predictive value of $98.8 \%$.

\section{DISCUSSION}

The prevalence of HIP is reported variably from 1.4 to $14 \%$ worldwide among different racial and ethnic groups. Prevalence is higher in Asian women than in Caucasian women. ${ }^{12}$ In Pakistan, prevalence of HIP has been reported from $4.2 \%$ to $26 \%$ due to wide variations in screening and diagnostic criteria. ${ }^{13,14}$ The prevalence of HIP in present study was $4.4 \%$ by fasting OGTT. While in South and North India, prevalence of HIP was between 6 and 7\%. ${ }^{15,16}$ Similar results were found in a study with the prevalence of $7.6 \%$ in US women. ${ }^{17}$

Increasing maternal age is an established risk factor for GDM. There was statistically significant difference in age between hyperglycemic and normoglycemic women. In present study the mean age of screen positive women was 29 years. Similarly, in a study by Sharma A et al. ${ }^{18}$ GDM was observed in $27.4 \%$ of women in age group of $>30$ years. The study by Terence $\mathrm{T}$ Lao et al. ${ }^{19}$ observed that risk of GDM increases significantly and progressively higher from 25 years onwards.

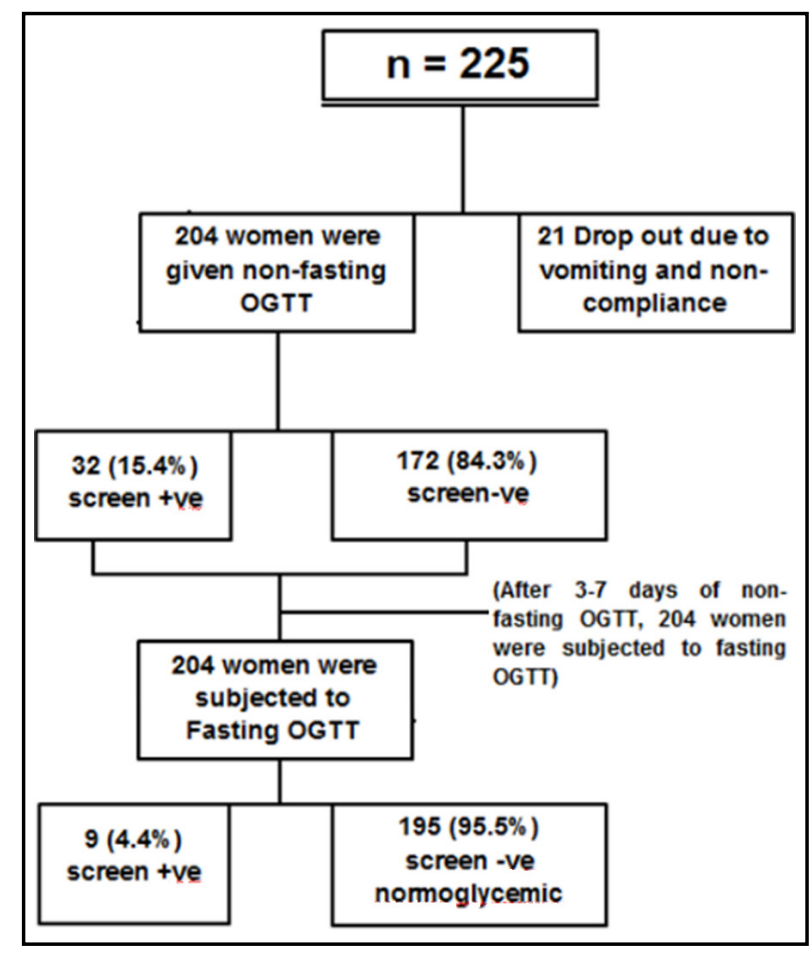

Fig.1: Consort Diagram. 
Table-II: Demography of study participants subjected to non-fasting OGTT ( $\mathrm{n}=204)$.

\begin{tabular}{|c|c|c|c|c|}
\hline \multirow{2}{*}{ Parameters } & & \multicolumn{2}{|c|}{ Non-fasting OGTT } & \multirow{2}{*}{ P-value } \\
\hline & & $\begin{array}{c}+v e \\
(n=32)\end{array}$ & $\begin{array}{c}-v e \\
(n=172)\end{array}$ & \\
\hline \multirow{6}{*}{ Age years } & \multirow{2}{*}{$<25$ Years } & 7 & 28 & \multirow{6}{*}{0.718} \\
\hline & & $21.9 \%$ & $16.3 \%$ & \\
\hline & 25-30 years & 13 & 79 & \\
\hline & $20-50$ years & $40.6 \%$ & $45.9 \%$ & \\
\hline & \multirow{2}{*}{$>30$ years } & 12 & 65 & \\
\hline & & $37.5 \%$ & $37.8 \%$ & \\
\hline \multirow{4}{*}{ Parity } & \multirow{2}{*}{$>=4$} & 12 & 47 & \multirow{4}{*}{0.244} \\
\hline & & $37.5 \%$ & $27.3 \%$ & \\
\hline & \multirow{2}{*}{$<4$} & 20 & 125 & \\
\hline & & $62.5 \%$ & $72.7 \%$ & \\
\hline \multirow{8}{*}{$\begin{array}{l}\text { Family } \\
\text { history of } \\
\text { diabetes }\end{array}$} & \multirow{2}{*}{ Father } & 6 & 15 & \multirow{8}{*}{0.000} \\
\hline & & $18.8 \%$ & $8.7 \%$ & \\
\hline & Mothor & 7 & 66 & \\
\hline & viotner & $21.9 \%$ & $38.4 \%$ & \\
\hline & \multirow{2}{*}{ Siblings } & 0 & 39 & \\
\hline & & $0.0 \%$ & $22.7 \%$ & \\
\hline & No Family & 19 & 52 & \\
\hline & History & $59.4 \%$ & $30.2 \%$ & \\
\hline \multirow{6}{*}{$\begin{array}{l}\text { Previ- } \\
\text { ous past } \\
\text { history of } \\
\text { gesta- } \\
\text { tional } \\
\text { diabetes } \\
\text { mellitus }\end{array}$} & Yes & 1 & 5 & \multirow{6}{*}{0.05} \\
\hline & res & $3.1 \%$ & $2.9 \%$ & \\
\hline & No & 29 & 166 & \\
\hline & & $90.6 \%$ & $96.5 \%$ & \\
\hline & Don't & 2 & 1 & \\
\hline & Know & $6.3 \%$ & $0.6 \%$ & \\
\hline \multirow{6}{*}{$\begin{array}{l}\text { Gesta- } \\
\text { tional } \\
\text { Age } \\
\text { weeks }\end{array}$} & $<14$ wroekc & 11 & 37 & \multirow{6}{*}{0.037} \\
\hline & - 14 weeks & $34.4 \%$ & $21.5 \%$ & \\
\hline & $14-28$ & 18 & 83 & \\
\hline & weeks & $56.3 \%$ & $48.3 \%$ & \\
\hline & \multirow{2}{*}{ >28 weeks } & 3 & 52 & \\
\hline & & $9.4 \%$ & $30.2 \%$ & \\
\hline
\end{tabular}

Chi-square test was applied with p-value 0.5 was considered as significant.

The risk of GDM increases with increasing gestational age because of increased placental contra-insulin hormones and increasing insulin resistance, it is because of this that the usual recommendations for GDM screening is between 24 and 28 weeks of gestation. ${ }^{20}$

According to the latest National Survey, ${ }^{1}$ almost $25 \%$ of the population in Pakistan is suffering from Type-2 diabetes mellitus (T2DM), 76.2\% and $62.1 \%$ are overweight and obese, respectively. Obesity, higher body mass index (BMI), and insulin resistance are added risk factors for undiagnosed diabetes in early pregnancy. ${ }^{21}$ Metabolic testing outside the pregnancy is not commonly performed, this increases the need for early screening during pregnancy to identify and treat dysglycemia before the period of rapid fetal organogenesis from 0 to 8 weeks to avert congenital fetal anomalies. ${ }^{22}$

In present study $34.4 \%$ of women were detected with hyperglycaemia who attended antenatal clinic in first trimester. It is necessary to initiate screening earlier in pregnancy as undiagnosed and untreated hyperglycemia during organogenesis can be toxic to fetal DNA and may increase the risk of fetal congenital anomalies. ${ }^{9}$

In this study majority of women attended antenatal clinic late in second trimester of gestation and $53.6 \%$ of them were found to be screen positive. The detection rate similarly increased by $44.4 \%,{ }^{23}$ $38 \%,{ }^{24}$ and $31.8 \%,{ }^{13}$ with increasing period of gestation in other studies as well.

In present study there is inverse relationship of parity and GDM, $62.5 \%$ of screen positive women were having less than four children whereas studies show increased risk of developing GDM with increasing age and parity. ${ }^{25-27}$

Family history of diabetes is a major risk factor for development of GDM. ${ }^{10,18,28}$ In this study, family history of diabetes was present in about 13 (40.6\%) women, whereas $20 \%$ of their parents were found to have diabetes, while their siblings did not give any history of diabetes. In present study $90.6 \%$ of screen positive women did not give previous history of GDM, possible reasons could be that women did not know or were not screened in previous pregnancies or due to lack of uniform screening methodology. Other studies also report that women did not know about previous history of GDM., ${ }^{1,29}$

In present study the sensitivity of non-fasting OGTT compared with fasting OGTT was $77.7 \%$ and specificity $87.1 \%$. Similar results were observed with sensitivity of $76.1 \%$ and specificity of $96.3 \%$ in study conducted by Tripathi $\mathrm{R}$ et $a .^{30}$ Using nonfasting OGTT other studies also reported $98-100 \%$ sensitivity and specificity with no statistically significant difference $(\mathrm{P}>0.05)$ between non fasting 
and fasting OGTT. ${ }^{10,15,31}$ The higher sensitivity seen in these studies may be because of risk based selection and women were screened in advanced gestational age. A recent study by Mohan $\mathrm{V}$ et al, ${ }^{32}$ has shown low sensitivity of non-fasting OGTT compared to the fasting OGTT (sensitivity $22.6 \%$, specificity $97.8 \%$ ).

The important finding in this study was that out of 204 study subjects only one woman had fasting hyperglycemia. Other studies also show that the fasting plasma glucose is inherently much lower in Asians than Caucasians as compared to post prandial values. ${ }^{33,34}$ In present study there were substantial number of women $(10.7 \%)$ who were detected as false positive by non-fasting OGTT, this may cause unnecessary apprehension and anxiety in the women and the family as the pregnancy is not a good time to give bad news. In spite of this low positive predictive value (PPV $21.8 \%$ ) of single non-fasting OGTT, this can be considered as a pragmatic screening test in view of its high negative predictive value $(98.84 \%)$ with less chances of missing true cases.

Limitations of the study: It is a cross sectional single centered study with a limited generalizability. Further multicenter studies may be conducted with larger sample size.

Strength of the study: The strength of the study was that all study participants were subjected to fasting and non-fasting blood glucose test, which reduced the bias and may have improved sensitivity and specificity of the screening test.

\section{CONCLUSION}

The use of the non-fasting OGTT as a universal single step screening test at first antenatal visit may be a practical and pragmatic approach to detect HIP in the resource constrained settings as screening and diagnostic tool.

High sensitivity is important for any screening test but higher negative predictive value also has an important role so that true cases are not missed. This study supports the concept of universal screening using single non-fasting OGTT for screening and diagnosis of HIP with less chances of missing GDM. Where resources permit, fasting OGTT or IADPSG criteria may be undertaken as per global recommendations and practices.

Acknowledgements: Authors would like to acknowledge Prof. Saleh Memon, Professor of Ophthalmology, Isra University, Karachi-
Campus, for his guidance, help, encouragement and support. Our gratitude to Prof. Abdul Basit, Professor of Medicine, Baqai Institute of Diabetes and Endocrinology (BIDE) for his kind review and support. The authors would also like to express deepest thanks and appreciation to Mr. Faisal Faheem, Mr. Javed Jabbar and Mr. Syed Imran Shah for their statistical, IT support and formatting of the manuscript.

Funding Details: Isra University and Hospital, Karachi Campus provided complimentary laboratory services for blood glucose estimation.

Informed Consent: Written informed consent was taken from study participants.

Conflict of Interest: None.

Grant Support E Financial Disclosures: None.

\section{REFERENCES}

1. Basit A, Fawwad A, Qureshi H, Shera AS, NDSP Members. Prevalence of diabetes, pre-diabetes and associated risk factors: Second National Diabetes Survey of Pakistan (NDSP), 2016-2017. BMJ Open. 2018;8:e20961. doi: 10.1136/ bmjopen-2017-020961

2. Reddy KM, Sailaja PL, Balmuri S, Jagarlamudi A, Betha K. Prevalence of gestational diabetes mellitus and perinatal outcome: A rural tertiary teaching hospital-based study. Int J Reprod Contracept Obstet Gynecol 2017;6(8):35943598. doi: 10.18203/2320-1770.ijrcog20173491

3. International Diabetes Federation. IDF Diabetes Atlas, 6th edn. Brussels, Belgium: International Diabetes Federation, 2013. Online version of IDF Diabetes Atlas: www.idf.org/ diabetesatlas

4. Veeraswamy S, Vijayam B, Gupta VK, Kapur A. Gestational diabetes: The public health relevance and approach. Diabetes Res Clin Pract. 2012;97(3):350-358. doi: 10.1016/j. diabres.2012.04

5. Badikillaya VU, Adusumalli P, Venkata RG, Pernenkil S. Effectiveness of Diabetes in Pregnancy Study Group India (DIPSI) Diagnostic Criterion in Detecting Gestational Diabetes Mellitus - a Pilot Study in a Rural Population. Indian J Basic Appl Med Res. 2013;2(6):614-618.

6. Maternal Health Division Ministry of Health and Family Welfare Government of India, Maternal and Health Division, National Guidelines for Diagnosis and Management of Gestational Diabetes Mellitus. New Delhi, India:, New Concept Information Systems; 2014.(Not in Vancouver style)

7. Rani PR, Begum J. Screening and Diagnosis of Gestational Diabetes Mellitus, Where Do We Stand. J ClinDiagn Res. 2016;10(4):QE01-4. doi: 10.7860/JCDR/2016/17588.7689

8. Agarwal MM. Gestational diabetes mellitus: Screening with fasting plasma glucose. World J Diabetes. 2016;7(14):279289. doi: $10.4239 /$ wjd.v7.i14.279

9. Alberti KG, Zimmet PZ. Definition, diagnosis and classification of diabetes mellitus and its complications. Part 1: diagnosis and classification of diabetes mellitus provisional report of a WHO consultation. Diabet Med. 1998;15(7):539-553. doi: 10.1002/(SICI)10969136(199807)15:7<539::AID-DIA668>3.0.CO;2-S 
10. Anjalakshi C, Balaji V, Balaji MS, Ashalata S, Suganthi $\mathrm{S}$, Arthi $\mathrm{T}$, et al. A single test procedure to diagnose gestational diabetes mellitus. Acta Diabetol. 2009;46(1):5154. doi: 10.1007/s00592-008-0060-9

11. International Association of Diabetes and Pregnancy Study Groups Consensus Panel, Metzger BE, Gabbe SG, Persson B, Buchanan TA, Catalano PA, Damm P, et al. International association of diabetes and pregnancy study groups recommendations on the diagnosis and classification of hyperglycemia in pregnancy. Diabet Care. 2010;33(3):676682. doi: $10.2337 / \mathrm{dc} 09-1848$

12. Yuen L, Wong VW. Gestational diabetes mellitus: Challenges for different ethnic groups. World J Diabet. 2015;6(8):1024-1032. doi:10.4239/wjd.v6.i8.1024

13. Bibi S, Saleem U, Mahsood N. The frequency of gestational diabetes mellitus and associated risk factors at Khyber teaching hospital Peshawar. J Postgrad Med Inst. 2015;29(1):43-46.

14. Zaman N, Taj N, Nazir S, Ullah E, Fatima N. Gestational diabetes mellitus and obesity: An experience at a teaching hospital in Bahawalpur, Pakistan. Rawal Med J. 2013;38:165-168.

15. Sharma K, Wahi P, Gupta A, Jandial K, Bhagat R, Gupta R, et al. Single glucose challenge test procedure for diagnosis of gestational diabetes mellitus: a Jammu cohort study. J Assoc Physicians India. 2013;61(8):558-559.

16. Wahi P, Dogra V, Jandial K, Bhagat R, Gupta R, Gupta S, et al. Prevalence of gestational diabetes mellitus (GDM) and its outcomes in Jammu region. J Assoc Physicians India. 2011;59:227-230.

17. Casagrande SS, Linder B, Cowie CC. Prevalence of gestational diabetes and subsequent Type 2 diabetes among U.S. women. Diabetes Res ClinPract. 2018;141:200208. doi: 10.1016/j.diabres.2018.05.010

18. Sharma A, Gupta M, Agrawal A. Comparison of diagnostic accuracy of two one step procedures for screening of gestational diabetes mellitus. Int J Reprod Contracept Obstet Gynecol. 2015;4:81-85. doi: 10.5455/2320-1770. ijrcog20150216

19. Lao TT, Ho LF, Chan BC, Leung WC. Maternal age and prevalence of gestational diabetes mellitus. Diabet Care. 2006;29(4):948-949. doi: 10.2337/diacare.29.04.06.dc05-2568

20. American Diabetes Association. Diabetes Care 2002;25(Suppl-1):s94-s96. doi: 10.2337/diacare.25.2007.S94

21. Harreiter J, Simmons D, Desoye G, Corcoy R, Adelantado JM, Devlieger R, et al. IADPSG and WHO 2013 gestational diabetes mellitus criteria identify obese women with marked insulin resistance in early pregnancy. Diabet Care. 2016;39:e90-e92.

22. Masood SN, Baqai S, Naheed F, Masood Y, Sikandar $\mathrm{R}$, Chaudhri $\mathrm{R}$, et al. Guidelines for management of hyperglycemia in pregnancy (HIP) by Society of Obstetricians \& Gynaecologists of Pakistan (SOGP). J Diabetol. 2021;12:83-98.

23. Akram N, Butt F. Universal Screening with Glucose Challenge Test in Detection of Gestational Diabetes. Biomedica. 2014;30(1):29-33.

24. Bancroft K, Tuffnell DJ, Mason GC, Rogerson LJ, Mansfield M. A randomised controlled pilot study of the management of gestational impaired glucose tolerance. BJOG. 2000;107(8):959-963. doi: 10.1111/ j.1471-0528.2000.tb10396.x
25. Zargar AH, Sheikh MI, Bashir MI, Masoodi SR, Laway BA, Wani AI, et al. Prevalence of gestational diabetes mellitus in Kashmiri women from the Indian subcontinent. Diabetes Res Clin Pract. 2004;66(2):139-145. doi: 10.1016/j. diabres.2004.02.023

26. Kalyani KR, Jajoo S, Hariharan C, Samal S. Prevalence of gestational diabetes mellitus, its associated risk factors and pregnancy outcomes at a rural setup in Central India. Int J Reprod Contracept Obstet Gynecol. 2014;3(1):219-224.

27. King $H$. Epidemiology of glucose intolerance and gestational diabetes in women of childbearing age. Diabetes Care. 1998;21(Suppl-2):B9-B13

28. Vij P, Jha S, Gupta SK, Aneja A, Mathur R, Waghdhare S, et al. Comparison of DIPSI and IADPSG criteria for diagnosis of GDM: A study in a north Indian tertiary care center. Int J Diabetes Dev Ctries. 2015;35(3):285-288.

29. Hussain Z, Yusoff ZM, Sulaiman SA. Evaluation of knowledge regarding gestational diabetes mellitus and its association with glycaemic level: A Malaysian study. Prim Care Diabetes. 2015;9(3):184-90. doi: 10.1016/j. pcd.2014.07.007

30. Tripathi R, Verma D, Gupta VK, Tyagi S, Kalaivani M, Ramji S, et al. Evaluation of $75 \mathrm{~g}$ glucose load in nonfasting state [Diabetes in Pregnancy Study group of India (DIPSI) criteria] as a diagnostic test for gestational diabetes mellitus. Indian J Med Res. 2017;145(2):209-214. doi: 10.4103/ijmr.IJMR_1716_15

31. Saxena P, Verma P, Goswami B. Comparison of Diagnostic Accuracy of Non-fasting DIPSI and HbA1c with Fasting WHO Criteria for Diagnosis of Gestational Diabetes Mellitus. J Obstet Gynaecol India. 2017;67(5):337-342. doi:10.1007/s13224-017-0962-y

32. Mohan V, Mahalakshmi MM, Bhavadharini B, Maheswari $\mathrm{K}$, Kalaiyarasi G, Anjana RM, et al. Comparison of screening for gestational diabetes mellitus by oral glucose tolerance tests done in the non-fasting (random) and fasting states. Acta Diabetol. 2014;51(6):1007-1013. doi: 10.1007/s00592014-0660-5

33. Wijeyaratne $\mathrm{CN}$, Ginige $\mathrm{S}$, Arasalingam A, Egodage C, Wijewardhena K. Screening for gestational diabetes mellitus: The Sri Lankan experience. Ceylon Med J. 2006;51(2):53-58. doi: 10.4038/cmj.v51i2.1353

34. Agarwal MM, Dhatt GS, Punnose J, Koster G. Gestational diabetes in a high-risk population: using the fasting plasma glucose to simplify the diagnostic algorithm. Eur J Obstet Gynecol Reprod Biol. 2005;120(1):39-44. doi: 10.1016/j. ejogrb.2004.07.034

\section{Authors' Contribution:}

SNM \& NL: Conception, design, drafting and intellectual content analysis.

SS: Conception and acquisition of data.

YM: Manuscript design, interpretation of data and statistical analysis.

SNM: Responsible and accountable for the integrity of the work. 